\title{
Evaluation of Castration-Resistant Prostate Cancer with Androgen Receptor-Axis Imaging
}

\author{
Neeta Pandit-Taskar ${ }^{1}$, Darren R. Veach ${ }^{1}$, Josef J. Fox ${ }^{1}$, Howard I. Scher ${ }^{2}$, Michael J. Morris ${ }^{2}$, and Steven M. Larson ${ }^{1}$ \\ ${ }^{I}$ Department of Radiology, Memorial Sloan Kettering Cancer Center, New York, New York; and ${ }^{2}$ Department of Medicine, Memorial \\ Sloan Kettering Cancer Center, New York, New York
}

\begin{abstract}
Castration-resistant prostate cancer (CRPC) is the lethal form of prostate cancer, and more than 26,000 men will die from this disease in 2016. The pathophysiology of CRPC is clearly multifactorial, but most often, androgen receptor (AR) upregulation is associated with its earliest beginnings and the AR increase is part of the multimolecular complex including downstream effector proteins linked to AR (AR-axis) responsible for rapid proliferation and malignant features of the malignant cell. In both animal models and patients, glycolysis (Warburg effect) is also an early manifestation of CRPC transformation. At Memorial Sloan Kettering Cancer Center, we have focused our energies on imaging studies of the AR-axis in CRPC, using ${ }^{18} \mathrm{~F}-\mathrm{FDG}$, ${ }^{18} \mathrm{~F}-16 \beta$-fluoro-5a-dihydrotestosterone $\left({ }^{18} \mathrm{~F}-\mathrm{FDHT}\right)$, and a variety of radiolabeled antibodies targeting downstream effectors, such as prostate-specific membrane antigen (PSMA). Small-molecularweight PSMA-targeting agents are not part of this review. In this review, we will focus on molecular imaging of the AR-axis in metastatic CRPC (mCRPC) and discuss our personal experience with these tracers. Our goal is to put these radiopharmaceuticals in the context of mCRPC biology and diagnosis (e.g., $\left.{ }^{18} \mathrm{~F}-\mathrm{FDHT}\right)$.
\end{abstract}

Key Words: molecular imaging; oncology: GU; radioimmunoimaging; androgen receptor-axis imaging; CRPC; castration-resistant prostate cancer

J Nucl Med 2016; 57:73S-78S

DOI: 10.2967/jnumed.115.170134

$\mathbf{P}$ rostate cancer, when detected before spread from the prostate gland, may be completely eradicated by surgery or local radiotherapy. Approximately one third of patients will fail primary treatment, and a rising prostate-specific antigen (PSA) level will herald the onset of recurrent or metastatic tumor. At this stage, PSA levels will usually decline with hormonal castration to levels of androgen hormone below $50 \mathrm{ng} / \mathrm{dL}$. Typically, in castrate patients, PSA begins to rise again within approximately 16-18 mo (median) despite castration, heralding the onset of CRPC.

Received Jul. 14, 2016; revision accepted Aug. 15, 2016.

For correspondence or reprints contact: Steven M. Larson, Department of Radiology, Memorial Sloan Kettering Cancer Center, 1275 York Ave., New York, NY 10065.

E-mail: larsons@mskcc.org.

COPYRIGHT (c) 2016 by the Society of Nuclear Medicine and Molecular Imaging, Inc.

\section{MOLECULAR IMAGING OF AR WITH ${ }^{18}$ F-FDHT}

\section{Discovery and Clinical Translation of ${ }^{18} \mathrm{~F}-\mathrm{FDHT}$}

John Katzenellenbogen at the University of Illinois (UrbanaChampaign) and Michael Welch at Washington University (St. Louis) developed steroid-based radioligands with sufficient affinity to hormone receptors (i.e., estrogen receptor/AR) to quantify receptor status in breast and prostate cancer patients using whole-body PET. The highly versatile and easily obtained isotope ${ }^{18} \mathrm{~F}$ with its 110-min half-life was chosen for labeling (1-3). In vitro and in vivo biologic data demonstrated that ${ }^{18} \mathrm{~F}-\mathrm{FDHT}$ was the best choice for AR imaging in prostate cancer in light of its good balance of in vivo stability, ease of production, and similar binding affinity for AR, while retaining selectivity from other nuclear receptors (e.g., estrogen receptor, glucocorticoid receptor, and progesterone receptor) (Supplemental Fig. 1 [supplemental materials are available at http://jnm.snmjournals.org]).

The study that set the stage for clinical translation was imaging in baboons showing good, saturable focal uptake in AR-positive tissue, with an excellent tumor-to-background ratio (4). About $8 \mathrm{y}$ later, the first in-human PET imaging studies in castrate patients were reported by Memorial Sloan Kettering Cancer Center and Washington University (5-7). The production methodology developed by Washington University continues to be used to this day, though recent improvements have been made in the radiosynthetic chemistry $(8)$ and to the production process by automation $(9,10)$.

\section{Pharmacokinetics of ${ }^{18} \mathrm{~F}-\mathrm{FDHT}$}

Administered as an intravenous infusion in the brachial vein, a typical dose of 185-370 MBq (5-10 mCi) of ${ }^{18}$ F-FDHT (1-4 nmol; $0.3-1.2 \mu \mathrm{g}$ mass) rapidly binds to serum proteins and albumin- and sex hormone-binding globulin-bound state in blood, as one would expect for a hydrophobic steroid (Fig. 1) (6). In men, most intact ${ }^{18}$ F-FDHT has a plasma half-life of only 5-7 min and clears from the bloodstream in 15 min (Fig. 2A) (6). Via primarily hepatic metabolism, radiometabolites appear over the same timeframe, and the system plateaus at $20 \mathrm{~min}$ after injection. The metabolites are excreted in the bile, and a portion is refluxed into the blood. Fortunately, the metabolites do not compete with ${ }^{18} \mathrm{~F}$-FDHT binding to AR.

Beattie et al. applied linear compartmental pharmacokinetic modeling to ${ }^{18} \mathrm{~F}$-FDHT uptake into tumor to a simple 2-compartment model in which the destination compartment was considered a permanent, unidirectional parameter, $\mathrm{k}_{\text {trap }}$, attributed to intramolecular transport and binding to AR; a population-based input function was calculated by averaging aorta region-of-interest data from dynamic PET scans of a 25-patient cohort (11) (Fig. 2B). This kinetic modeling approach shows that uptake by PET imaging correlates with AR expression levels. In a recent study supported 


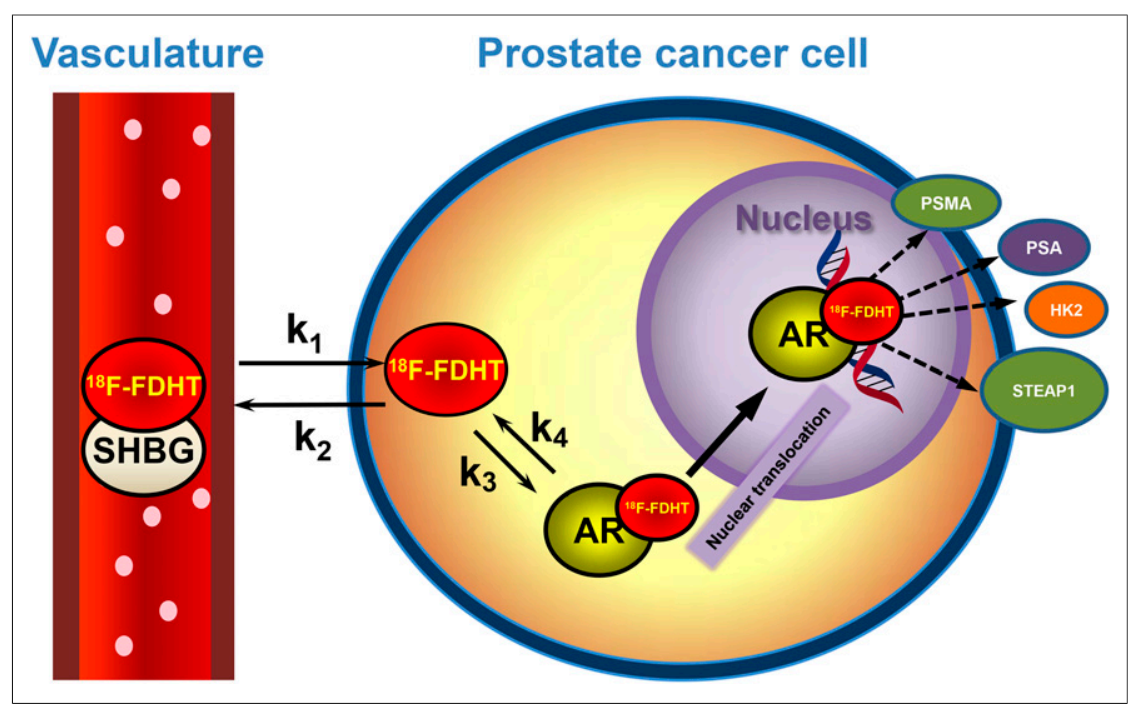

FIGURE 1. AR-axis PET imaging. ${ }^{18} \mathrm{~F}-\mathrm{FDHT}$ is high-affinity $\mathrm{DHT}$ analog binding $\mathrm{AR}$ in cytoplasm. ${ }^{18} \mathrm{~F}-\mathrm{FDHT}-\mathrm{AR}$ complex localizes to nucleus, where it binds hormone-responsive elements on DNA, activating androgen-linked proteins such as PSA (secreted), PSMA (membrane), HK2, and STEAP. These may be imaged with ${ }^{89} \mathrm{Zr}$-labeled antibodies.

by the Movember GAP2 project, these findings were confirmed and refined by Kramer et al. at VU Amsterdam, who reported an improvement over using body weight-normalized SUV in dynamic ${ }^{18}$ F-FDHT PET images of 31 lesions in a 4-patient cohort. They observed a high correlation $\left(R^{2}=0.97\right)$ between $\operatorname{SUV}_{A U C, P P}$ (SUV normalized to ${ }^{18} \mathrm{~F}$-FDHT plasma area under the curve) and an irreversible trapping constant in a 2-tissue-compartment model, using an input function derived from both PET and venous blood sample data to correct for metabolites (12). Such studies may make it more practical to obtain biologically relevant quantitation of receptor number.

\section{Clinical Molecular Imaging of AR in Men}

${ }^{18} \mathrm{~F}$-FDHT binds with high affinity to AR-expressing tumor tissues in men. Patient selection should include serum androgen measurements, because AR imaging is practical only in castrate
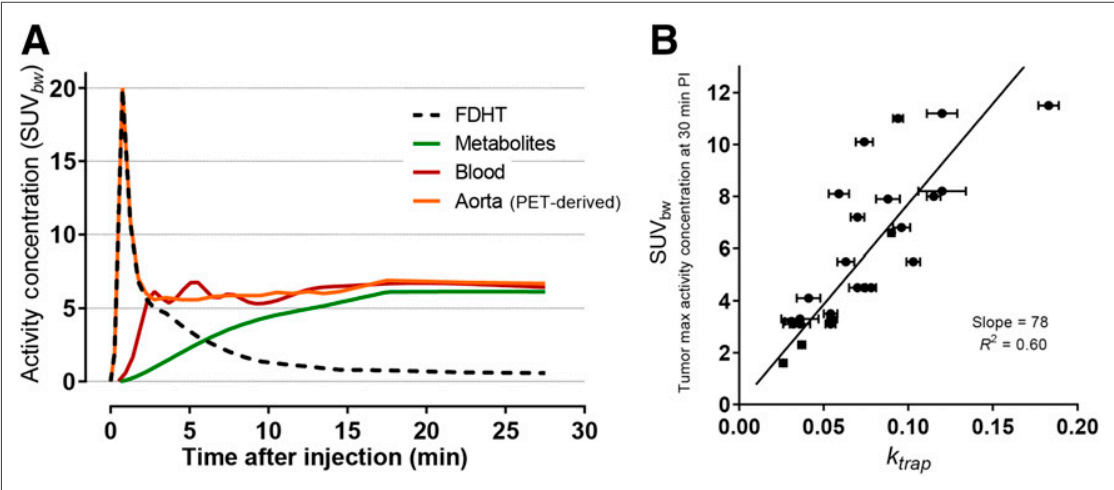

FIGURE 2. (A) Time-activity curves of ${ }^{18} \mathrm{~F}-\mathrm{FDHT}$ in $\mathrm{mCRPC}$ patient in body weight-corrected SUV units from PET region of interest-derived data (aorta) or blood sample data (11). (B) Scatterplot showing weak relationship between unidirectional rate constant, $k_{\text {trap }}$, and tumor SUV $V_{b w}$ (at $30 \mathrm{~min}$; normalized by body weight) for ${ }^{18} \mathrm{~F}$-FDHT PET in patients with prostate cancer. This linear regression analysis was constrained through origin. (Adapted with permission of (11).) patients (currently) with testosterone levels below $50 \mathrm{ng} / \mathrm{dL}$. The active radiotracer ${ }^{18} \mathrm{~F}-\mathrm{FDHT}$ is an agonist of $\mathrm{AR}$ and an analog of DHT, the most common androgen in prostate and prostate cancer at the cellular level in men. The ${ }^{18} \mathrm{~F}$-FDHT uptake, as quantified by $\mathrm{SUV}_{\text {max }}$ or related SUV parameter, plateaus within about $30 \mathrm{~min}$, with no further uptake thereafter. A single patient dose at the conservative 5-cGy threshold for diagnostic studies corresponded to $331 \mathrm{MBq}(8.9 \mathrm{mCi})$ (7).

An example of a PET imaging study using ${ }^{18} \mathrm{~F}-\mathrm{FDHT}$ is shown in Figure 3. Normally, subjects are studied within the same time window (a few days), with ${ }^{18}$ F-FDG as well, because we have found that there is considerable heterogeneity of biochemical features of individual CRPC lesions, when glycolysis and AR expression are compared. In addition, the companion CT provides anatomic orientation to lesion site.

\section{Hitting the Target: In Vivo}

Displacement of ${ }^{18}$ F-FDHT by AR

\section{Inhibitor Drugs}

In the last few years, high-affinity AR inhibitors have been developed and approved by the U.S. Food and Drug Administration for use in CRPC on the basis of prolonged survival. One of these, enzalutamide, has been studied in men, using ${ }^{18} \mathrm{~F}$-FDHT imaging to show whether or not the AR blockade of ${ }^{18} \mathrm{~F}-\mathrm{FDHT}$ uptake is occurring, as would be expected for effective therapy. Figure 4 shows in vitro and in vivo studies in support of the concept that ${ }^{18} \mathrm{~F}$-FDHT may be used as a probe to demonstrate the high-affinity binding requisite for pharmacologic AR blockade in vivo (13).

\section{Determining Biologically Effective Dose for AR Blockade}

In a first-in-human study of optimizing dosing schedules for a novel second-generation AR blockade drug, apalutamide, ${ }^{18} \mathrm{~F}$-FDHT was also used to explore progressive AR blockade in a phase I trial of dose escalation (Fig. 5) (14). Sixteen patients received a baseline and follow-up ${ }^{18} \mathrm{~F}$-FDHT scan during the course of dose escalation, with doses ranging from 30 to $390 \mathrm{mg}$. A backgroundcorrected $\mathrm{SUV}_{\max }$ was determined as previously described (15), and all lesions in individual patients were averaged. A mean of the $\mathrm{SUV}_{\text {max }}$ parameter at each drug level was then correlated with dose level, with saturation levels beginning at $120 \mathrm{mg}$. Because seizures had been observed at highest doses of other AR inhibitors, a final phase II dose of $240 \mathrm{mg}$ was chosen to ensure saturation and minimize neurotoxicity.

\section{PSMA IMAGING WITH RADIOLABELED ANTIBODIES}

\section{AR-Directed Agents and PSMA \\ Targeting with Antibodies}

PSMA is a well-established marker for prostate cancer that is highly expressed in prostate cancer cells. Although highly 


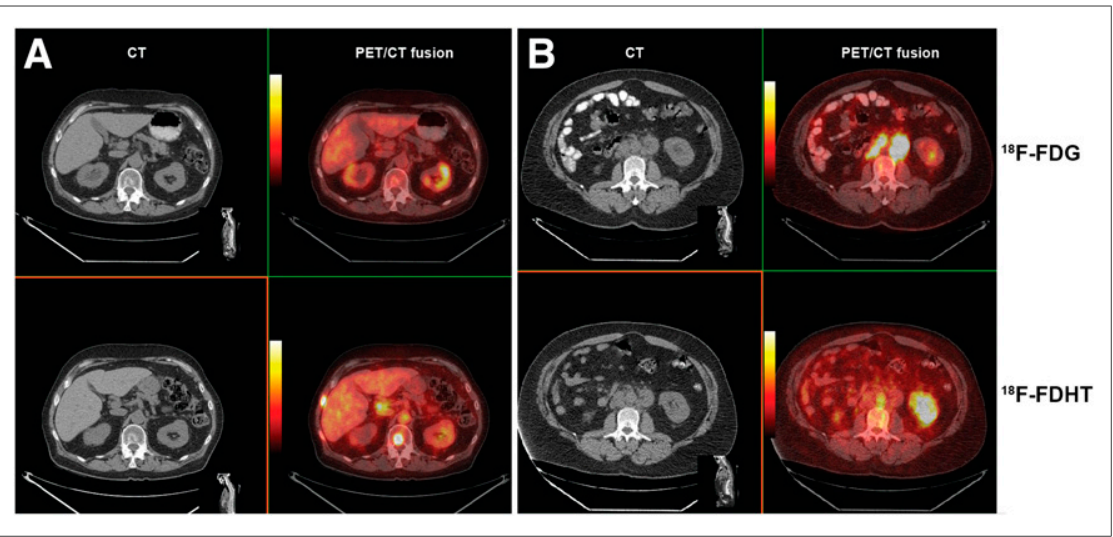

FIGURE 3. (A) CT and PET/CT fusion images showing relationship of CT findings and molecular imaging changes. CT scan shows osteoblastic rim around metastasis in the T-12 vertebrae body. ${ }^{18} \mathrm{~F}-\mathrm{FDG}$ image (top row) shows no localization in tumor-bearing site, whereas ${ }^{18} \mathrm{~F}-\mathrm{FDHT}$ image obtained $24 \mathrm{~h}$ later shows high-intensity uptake (bottom row). (B) CT and PET/CT fusion images in another patient with bulky metastasis in periaortic lymph nodes. ${ }^{18} \mathrm{~F}-\mathrm{FDG}$ imaging (top) shows avid uptake in bulky tumor-bearing lymph nodes, whereas ${ }^{18} \mathrm{~F}-\mathrm{FDHT}$ imaging performed $24 \mathrm{~h}$ later shows no nodal uptake (bottom). Note aortic activity of bound metabolite.

specific for prostate, it is also expressed in the cells of the small intestine, proximal renal tubules, and salivary glands $(16,17)$. However, the level of expression in the prostate cells is 100- to 1,000 -fold higher than in nonprostate tissue $(18,19)$. PSMA is a type II integral cell surface membrane protein that is not secreted, thereby making it an ideal target for monoclonal antibody $(\mathrm{mAb})$ imaging or therapy. PSMA has been found to have folate hydrolase and glutamate carboxypeptidase activity (2022). PSMA upregulation correlates with increased aggressiveness and recurrence $(23,24)$ and higher mortality $(25)$, suggesting a functional role of PSMA in prostate cancer progression.

PSMA-targeted imaging with ${ }^{111}$ In-labeled mAb was approved by the Food and Drug Administration as 7E11/CYT-356 Capromab (ProstaScint) to detect disease in patients (26-29). Initial clinical enthusiasm was tempered by the fact that $7 \mathrm{E} 11$

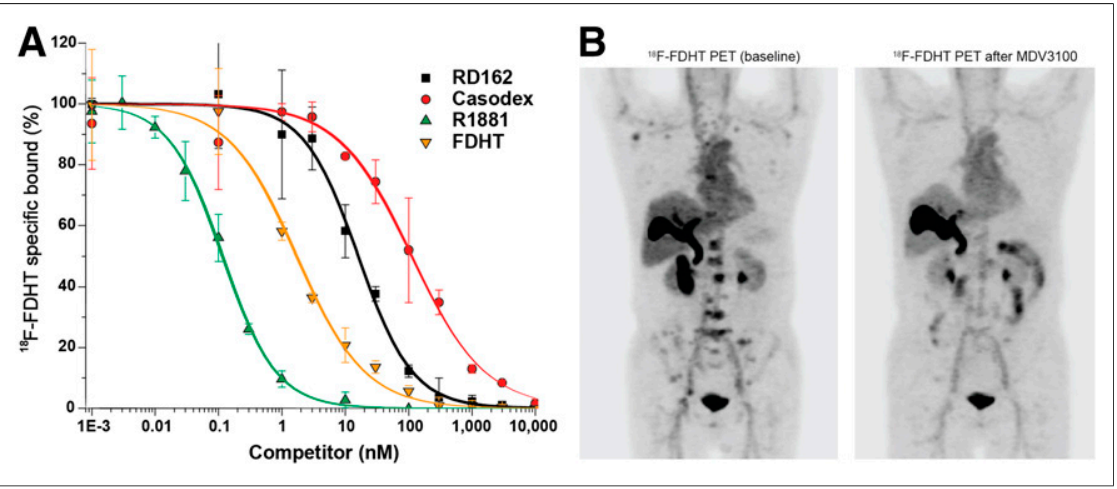

FIGURE 4. (A) In vitro displacement studies showing expected differences in range of displacement of ${ }^{18} \mathrm{~F}-\mathrm{FDHT}$, in proportion to binding affinity of several drugs that bind to AR in this assay. ${ }^{18} \mathrm{~F}-\mathrm{FDHT}$ and $\mathrm{DHT}$ (natural androgen) have a binding affinity similar to AR. Also shown are competitor drugs with higher affinity (R1881) and lower affinity (bicalutamide and RD162). (B) ${ }^{18} \mathrm{~F}-\mathrm{FDHT}$ PET imaging in patient with mCRPC. Note ${ }^{18} \mathrm{~F}-\mathrm{FDHT}$ uptake in patient's bones before treatment (left) and after therapeutic doses of daily enzalutamide (right). targets the internal portion of the PSMA molecule, which is less accessible, and targeting was suboptimal in intact cells versus necrotic tissue, and viable tumor was missed (30,31).

Given the limitation of Capromab, targeting of the extracellular domain of PSMA was explored (31-33) and found to be more effective. J591 binds to the external domain of PSMA with high-affinity binding to prostate cancer cells in tissue culture and animal models $(33,34)$.

\section{Imaging with Radiolabeled J591}

For human studies, J591 has been conjugated with a metal chelating agent (e.g., diethylene triamine pentaacetic acid or DOTA) to enable labeling with radiometals such as ${ }^{111}$ In or ${ }^{177} \mathrm{Lu}$ (35). More recently, J591 has been radiolabeled with a PET radioisotope, ${ }^{89} \mathrm{Zr}$, using the siderophore desferrioxamine as a chelator $(36,37)$.

Initial phase I studies of huJ591 tracelabeled with ${ }^{111}$ In using a DOTA chelate showed that repetitive dosing was well tolerated, with total doses of up to $500 \mathrm{mg} / \mathrm{m}^{2}$ without the development of a human antihumanized (deimmunized) antibody response $(38,39)$. No dose-limiting toxicity occurred, and the maximum tolerated dose was not reached. Excellent tumor targeting occurred at all dose levels of mAb. No mAb targeting to sites other than those involved by prostate cancer was observed, although, as seen in other trials using radiometals, the liver is the primary site of metabolism. Percentage injected dose in the liver diminished with increasing dose of antibody, and higher doses were associated with longer plasma clearance times (40).

In a dose escalation study, ${ }^{111}$ In-J591 antibody was given in combination with cold J591 administered in escalating doses from 25 to $100 \mathrm{mg}$. Dose-dependent plasma clearance of the antibody occurred more slowly as antibody mass increased up to $100 \mathrm{mg}$ (41). The mean biologic half-life was $0.96,1.9,2.75$, and $3.47 \mathrm{~d}$ for the 10-, 25-, 50-, and 100-mg doses, respectively. Hepatic saturation was achieved at a 10 - to $25-\mathrm{mg}$ dose of antibody, and the optimal tradeoff between increased J591 circulation and liver uptake was obtained with $25 \mathrm{mg}$ of total antibody dose (41).

In a detailed analysis of lesion targeting with ${ }^{111} \mathrm{In}$-J591, both bone and soft-tissue lesions were targeted well, with localization in about $94 \%$ of skeletal lesions detected by conventional imaging (42). Visualization of lesions was better in delayed images and at later infusions of higher antibody masses. Imaging was similarly high with ${ }^{177} \mathrm{Lu}-$ J591 (43).

PET allows for superior image resolution and ability to quantify uptake as compared with single-photon imaging, enabling 


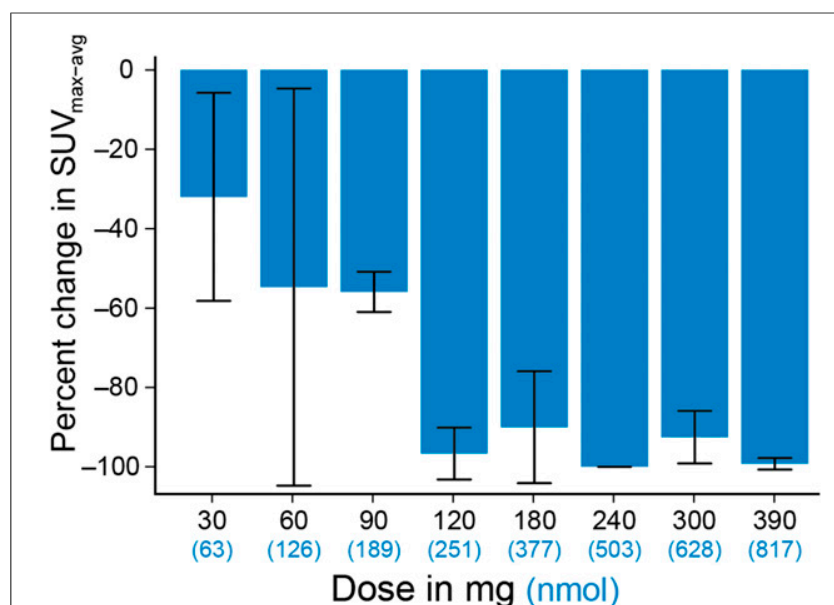

$\begin{array}{lllllllll}\text { No. of patients } & 2 & 2 & 2 & 2 & 2 & 1 & 4 & 1\end{array}$

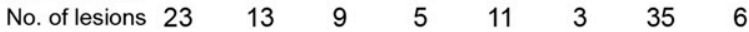

FIGURE 5. Percentage change from baseline in $S_{\text {mean }}$ average in cohorts of patients with mCRPC who were being treated with apalutamide, an AR inhibitor. Progressive decline in follow-up SUV is consistent with progressive saturation of AR at tumor site. (Modified from Figure 1 and reprinted with permission of (14).)

better dosimetry estimations for normal organs and tumors in vivo. ${ }^{89} \mathrm{Zr}$ has been increasingly used for immuno-PET imaging because of its favorable decay characteristics, including a radioactive half-life of $78.4 \mathrm{~h}$, which is more suitable for imaging antibody uptake. Chelation methodology using desferrioxamine has been described for labeling antibodies $(37,44)$, and preclinical studies with ${ }^{89} \mathrm{Zr}$-J591 have demonstrated excellent targeting of prostate cancer in vivo (44).

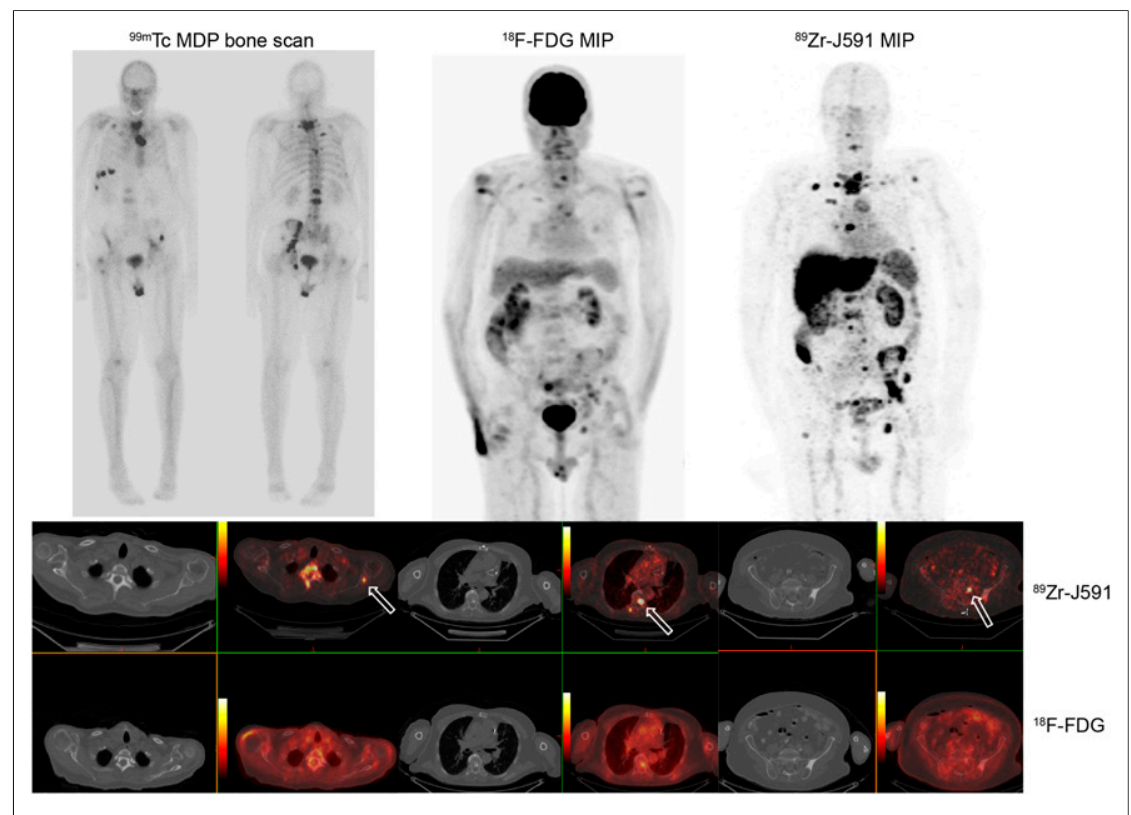

FIGURE 6. A 74-y-old man with prostate carcinoma with PSA 8.8. Bone scan showed multiple bone lesions that were stable. ${ }^{18} \mathrm{~F}-\mathrm{FDG}$ PET scan showed mild uptake in some but not all bone lesions. ${ }^{89} \mathrm{Zr}$-J591 PET imaging (upper, arrows) showed more extensive uptake and involvement of skeletal system, with uptake in a number of lesions not clearly seen on bone scan and that were also non-18 F-FDG-avid (lower). MIP = maximum-intensity projection.
In a first-in-human phase I study with ${ }^{89} \mathrm{Zr}$-J591 in prostate cancer patients, the clearance of ${ }^{89} \mathrm{Zr}$-J591 from serum was biexponential, with biologic half-lives of $7.0 \pm 4.5 \mathrm{~h}$ (range, 1.1-14 h) and $62 \pm 13 \mathrm{~h}$ (range, 51-89 h). Whole-body clearance was monoexponential, with a mean half-life of $219 \pm 48 \mathrm{~h}$ (range, 153-317 h). Dosimetric estimates to critical organs showed highest dose to the liver $(208 \pm 40.5 \mathrm{cGy} / \mathrm{GBq}[7.7 \pm 1.5 \mathrm{cGy} / \mathrm{mCi}])$, with lesser doses to renal cortex $(95 \pm 10.9 \mathrm{cGy} / \mathrm{GBq}[3.5 \pm 0.4 \mathrm{cGy} / \mathrm{mCi}])$ and bone marrow $(32 \pm 5.3 \mathrm{cGy} / \mathrm{GBq}[1.2 \pm 0.2 \mathrm{cGy} / \mathrm{mCi}])$. The optimal time for PET imaging after injection was $7 \pm 1 \mathrm{~d}$ (45).

A follow-up analysis of lesion targeting in 50 patients with CRPC imaged using ${ }^{89} \mathrm{Zr}-\mathrm{J} 591 \mathrm{PET} / \mathrm{CT}$ showed good localization of both bone and soft-tissue lesions (46). Higher targeting, including both uptake and lesion detection, was seen for bone lesions than for softtissue lesions. The median SUV was significantly higher for bone lesions than for soft-tissue lesions (8.9 vs. 4.8, respectively; $P<$ 0.00003). In a comprehensive comparative analysis with conventional imaging, ${ }^{89} \mathrm{Zr}$-J591 detected more osseous sites relative to conventional methylene diphosphonate bone scanning and CT scanning (Fig. 6). However, soft-tissue disease detection was inferior to CT scanning. Pathology correlation showed a high overall accuracy of ${ }^{89} \mathrm{Zr}-\mathrm{J} 591$ (95.2\%) for osseous lesions and slightly lower (60\%) for soft-tissue lesions.

Bayesian analysis was used to predict the number of positive lesions among the unbiopsied sites for each modality separately for bone and soft tissue (46). The results showed the highest predicted number of positive findings for J591 in osseous lesions, as compared with other conventional modalities (Supplemental Table 1).

\section{ANTI-PSMA MINIBODY IMAGING}

It has been shown that antibody fragments such as minibodies and diabodies clear faster and may allow for early imaging of tumor sites $(47,48)$. Fragments below 60 $\mathrm{kDa}$ are filtered through the glomerular system, leading to significant kidney excretion (49-52), which is not ideal for prostate cancer imaging agents; on the other hand, minibodies are slightly larger and do not have high renal clearance. IAB2M is an $80-\mathrm{kDa}$ minibody genetically engineered from the parent humanized anti-PSMA mAb J591, consisting of a bivalent homodimer, with each monomer comprising a single-chain variable fragment ( $\mathrm{scFv}$ ) linked to a human IgG1 $\mathrm{C}_{\mathrm{H}} 3$ domain, that targets the extracellular domain of PSMA (Supplemental Fig. 2). IAB2M lacks Fc receptor interaction domains on the minibody that make it pharmacologically inert to Fc-mediated effector functions (50-56).

In a phase I first-in-human study evaluating PET imaging with ${ }^{89} \mathrm{Zr}$ - IAB2M (57), there was rapid clearance of the minibody from the blood. Lesions were seen as early as $24 \mathrm{~h}$ after injection, with most lesions seen by $48 \mathrm{~h}$. Targeting to both bone and soft-tissue lesions (Fig. 7) and high correlation with pathology was observed. 


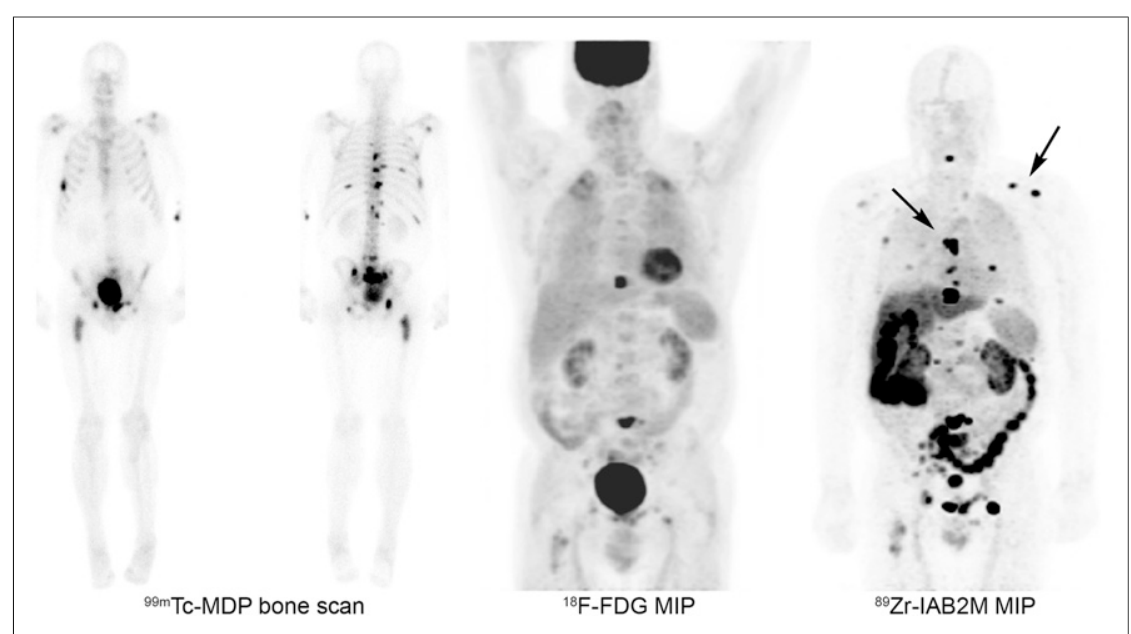

FIGURE 7. A 68-y-old man with prostate carcinoma with increasing level of PSA 24. Bone scan showed multiple stable bone lesions. ${ }^{18}$ F-FDG PET scan showed mild uptake in a few lesions. ${ }^{89} \mathrm{Zr}$-IAB2M PET imaging showed more lesions in skeletal system, with visualization of lesions not seen on bone scan or ${ }^{18} \mathrm{~F}-\mathrm{FDG}$ (arrows).

\section{CONCLUSION}

Prostate cancer is biologically heterogeneous, with clinical behavior ranging from more benign to lethal. Prostate cancer imaging with radionuclides has come a long way in the past decade, with the introduction of a variety of new agents that provide detection of early and late metastases for many of these clinical states, particularly early recurrence with PSA. Several reviews provide summaries of the role of molecular imaging agents for prostate cancer (e.g., Kircher et al. (58)). Our group has focused principally on $\mathrm{mCRPC}$, the lethal form of the disease, with tracers most relevant to AR-axis stimulation and growth, such as ${ }^{18} \mathrm{~F}-\mathrm{FDHT}$, ${ }^{18} \mathrm{~F}-\mathrm{FDG}$, and radioantibodies that target a variety of downstream effector proteins that can be used to monitor the response of tumor to treatment as well as the status of AR-axis activity in late stages of the disease, through PET imaging of antibodies. In this review, we have emphasized our work with AR imaging and PSMAtargeted antibodies.

From a clinical point of view, ${ }^{18} \mathrm{~F}$-FDHT has proven to be highly accurate for detecting the presence of AR (data not shown), which in turn is the most common driver of the CRPC state. The utility of ${ }^{18} \mathrm{~F}$-FDG comes from the ability to monitor treatment response in CRPC. ${ }^{18} \mathrm{~F}$-FDHT has proven uniquely useful in documenting the interaction of second-generation AR-axis inhibitors with AR binding in human tumors during clinical trials, and in this way has facilitated acceptance by regulatory agencies of these drugs for therapy in CRPC.

The explosion of interest in small molecules targeting PSMA, particularly in Europe (59), is one of the reasons we emphasized our studies with J591, a high-affinity anti-PSMA antibody. PSMA antibody imaging and therapy with radioantibodies is feasible and provides a specific technique to evaluate viable disease. Given certain practical limitations of longer circulation times of the antibody, methods to reduce circulation times and use of smaller molecules would be more suitable and should be further explored. PSMAtargeted therapeutics may offer another option for therapy especially in those with refractory disease (supplemental materials).

One final point: new targeting agents have recently been approved by the Food and Drug Administration, such as ${ }^{18} \mathrm{~F}$-fluciclovine (60),
${ }^{11} \mathrm{C}$-choline (61), and ${ }^{68} \mathrm{Ga}$-PSMA (59). All of these agents provide high-quality images and are documented to be useful for imageguided biopsy to detect occult tumors, especially in PSA recurrence after primary treatment of prostate cancer. Often, we are called on to choose the best molecular imaging agent, which is a difficult question; enthusiasm based on superb images is not proof. Instead, we propose considering biopsy-based approaches with careful statistics to estimate error rates, such as the Bayesian method illustrated in Supplemental Table 1. In a clinical research setting, in which we can perform a battery of tests on the same patients, comparison of $95 \%$ confidence for accuracy of individual tests allows us to rank-order the effectiveness of a new test-in this case, ${ }^{89} \mathrm{Zr}$-J591compared with standard tests, such as CT, ${ }^{18} \mathrm{~F}-\mathrm{FDG}$, and ${ }^{99 \mathrm{~m}} \mathrm{Tc}$ bone scanning. Each of these exciting new small molecules will have to be studied in a similar fashion, perhaps head-to-head, to choose which of these newly introduced imaging tracers will prove to be most effective.

\section{DISCLOSURE}

No potential conflict of interest relevant to this article was reported.

\section{REFERENCES}

1. Chen Y, Sawyers CL, Scher HI. Targeting the androgen receptor pathway in prostate cancer. Curr Opin Pharmacol. 2008;8:440-448.

2. Agus DB, Golde DW, Sgouros G, Ballangrud A, Cordon-Cardo C, Scher HI. Positron emission tomography of a human prostate cancer xenograft: association of changes in deoxyglucose accumulation with other measures of outcome following androgen withdrawal. Cancer Res. 1998;58:3009-3014.

3. Ido T, Wan CN, Casella V, et al. Labeled 2-deoxy-D-glucose analogs: F-18labeled 2-deoxy-2-fluoro-D-glucose, 2-deoxy-2-fluoro-D-mannose and C-14-2deoxy-2-fluoro-D-glucose. J Labelled Comp Radiopharm. 1978;14:175-183.

4. Bonasera TA, O'Neil JP, Xu M, et al. Preclinical evaluation of fluorine-18-labeled androgen receptor ligands in baboons. J Nucl Med. 1996;37:1009-1015.

5. Dehdashti F, Picus J, Michalski JM, et al. Positron tomographic assessment of androgen receptors in prostatic carcinoma. Eur J Nucl Med Mol Imaging. 2005;32:344-350.

6. Larson SM, Morris M, Gunther I, et al. Tumor localization of $16 \beta-{ }^{18}$ F-fluoro-5 $\alpha$ dihydrotestosterone versus ${ }^{18} \mathrm{~F}-\mathrm{FDG}$ in patients with progressive, metastatic prostate cancer. J Nucl Med. 2004;45:366-373.

7. Zanzonico PB, Finn R, Pentlow KS, et al. PET-based radiation dosimetry in man of ${ }^{18} \mathrm{~F}$-fluorodihydrotestosterone, a new radiotracer for imaging prostate cancer. J Nucl Med. 2004;45:1966-1971.

8. Zhou D, Lin M, Yasui N, et al. Optimization of the preparation of fluorine-18labeled steroid receptor ligands 16 alpha- $\left[{ }^{18} \mathrm{~F}\right]$ fluoroestradiol (FES), $\left[{ }^{18} \mathrm{~F}\right]$ fluoro furanyl norprogesterone (FFNP), and 16beta- $\left[{ }^{18} \mathrm{~F}\right]$ fluoro-5alpha-dihydrotestosterone (FDHT) as radiopharmaceuticals. J Labelled Comp Radiopharm. 2014;57: 371-377.

9. Lazari M, Lyashchenko SK, Burnazi EM, Lewis JS, van Dam RM, Murphy JM. Fully-automated synthesis of $16 \beta-{ }^{18}$ F-fluoro- $5 \alpha$-dihydrotestosterone (FDHT) on the ELIXYS radiosynthesizer. Appl Radiat Isot. 2015;103:9-14.

10. Ackermann U, Lewis JS, Young K, et al. Fully automated synthesis of $\left[{ }^{18} \mathrm{~F}\right]$ fluoro-dihydrotestosterone $\left(\left[{ }^{18} \mathrm{~F}\right] \mathrm{FDHT}\right)$ using the FlexLab module. $J$ Labelled Comp Radiopharm. 2016;59:424-428.

11. Beattie BJ, Smith-Jones PM, Jhanwar YS, et al. Pharmacokinetic assessment of the uptake of $16 \beta-{ }^{18} \mathrm{~F}$-fluoro-5 $\alpha$-dihydrotestosterone (FDHT) in prostate tumors as measured by PET. J Nucl Med. 2010;51:183-192. 
12. Kramer G, Yaqub M, Schuit R, et al. Assessment of simplified methods for quantification of $\left[{ }^{18} \mathrm{~F}\right] \mathrm{FDHT}$ uptake in patients with metastasized castrate-resistant prostate cancer [abstract]. J Nucl Med. 2016;57(suppl 2):464.

13. Scher HI, Beer TM, Higano CS, et al. Antitumour activity of MDV 3100 in castration-resistant prostate cancer: a phase 1-2 study. Lancet. 2010;375:1437-1446.

14. Rathkopf DE, Morris MJ, Fox JJ, et al. Phase I study of ARN-509, a novel antiandrogen, in the treatment of castration-resistant prostate cancer. $J$ Clin Oncol. 2013;31:3525-3530.

15. Fox JJ, Autran-Blanc E, Morris MJ, et al. Practical approach for comparative analysis of multilesion molecular imaging using a semiautomated program for PET/CT. J Nucl Med. 2011;52:1727-1732.

16. Israeli RS, Grob M, Fair WR. Prostate-specific membrane antigen and other prostatic tumor markers on the horizon. Urol Clin North Am. 1997;24:439-450.

17. Israeli RS, Powell CT, Corr JG, Fair WR, Heston WD. Expression of the prostatespecific membrane antigen. Cancer Res. 1994;54:1807-1811.

18. Silver DA, Pellicer I, Fair WR, Heston WD, Cordon-Cardo C. Prostate-specific membrane antigen expression in normal and malignant human tissues. Clin Cancer Res. 1997;3:81-85.

19. Sokoloff RL, Norton KC, Gasior CL, Marker KM, Grauer LS. A dual-monoclonal sandwich assay for prostate-specific membrane antigen: levels in tissues, seminal fluid and urine. Prostate. 2000;43:150-157.

20. Carter RE, Feldman AR, Coyle JT. Prostate-specific membrane antigen is a hydrolase with substrate and pharmacologic characteristics of a neuropeptidase. Proc Natl Acad Sci USA. 1996;93:749-753.

21. Heston WD. Characterization and glutamyl preferring carboxypeptidase function of prostate-specific membrane antigen: a novel folate hydrolase. Urology. 1997;49:104-112.

22. Pinto JT, Suffoletto BP, Berzin TM, et al. Prostate-specific membrane antigen: a novel folate hydrolase in human prostatic carcinoma cells. Clin Cancer Res. 1996;2:1445-1451.

23. Perner S, Hofer MD, Kim R, et al. Prostate-specific membrane antigen expression as a predictor of prostate cancer progression. Hum Pathol. 2007;38:696-701.

24. Ross JS, Sheehan CE, Fisher HA, et al. Correlation of primary tumor prostatespecific membrane antigen expression with disease recurrence in prostate cancer. Clin Cancer Res. 2003;9:6357-6362.

25. Kasperzyk JL, Finn S, Hendrickson W, et al. PSMA expression and prostate cancer survival. Paper presented at: Multi-Institutional Prostate Cancer SPORE Meeting; April 12-14; 2010; Fort Lauderdale, FL.

26. Babaian RJ, Sayer J, Podoloff DA, Steelhammer LC, Bhadkamkar VA, Gulfo JV. Radioimmunoscintigraphy of pelvic lymph nodes with ${ }^{111}$ indium-labeled monoclonal antibody CYT-356. J Urol. 1994;152:1952-1955.

27. Kahn D, Williams RD, Seldin DW, et al. Radioimmunoscintigraphy with ${ }^{111}$ indium labeled CYT-356 for the detection of occult prostate cancer recurrence. J Urol. 1994;152:1490-1495.

28. Kahn D, Williams RD, Manyak MJ, et al. ${ }^{111}$ Indium-capromab pendetide in the evaluation of patients with residual or recurrent prostate cancer after radical prostatectomy. The ProstaScint Study Group. J Urol. 1998;159:2041-2046.

29. Kahn D, Williams RD, Haseman MK, Reed NL, Miller SJ, Gerstbrein J. Radioimmunoscintigraphy with In-111-labeled capromab pendetide predicts prostate cancer response to salvage radiotherapy after failed radical prostatectomy. J Clin Oncol. 1998;16:284-289.

30. Troyer JK, Feng Q, Beckett ML, Wright GL Jr. Biochemical characterization and mapping of the 7E11-C5.3 epitope of the prostate-specific membrane antigen. Urol Oncol. 1995;1:29-37.

31. Troyer JK, Beckett ML, Wright GL Jr. Location of prostate-specific membrane antigen in the LNCaP prostate carcinoma cell line. Prostate. 1997;30:232-242.

32. Fair WR, Israeli RS, Heston WD. Prostate-specific membrane antigen. Prostate. 1997;32:140-148.

33. Liu H, Moy P, Kim S, et al. Monoclonal antibodies to the extracellular domain of prostate-specific membrane antigen also react with tumor vascular endothelium. Cancer Res. 1997;57:3629-3634.

34. Liu H, Rajasekaran AK, Moy P, et al. Constitutive and antibody-induced internalization of prostate-specific membrane antigen. Cancer Res. 1998;58:4055-4060.

35. Smith-Jones PM, Vallabhajosula S, Navarro V, Bastidas D, Goldsmith SJ, Bander NH. Radiolabeled monoclonal antibodies specific to the extracellular domain of prostate-specific membrane antigen: preclinical studies in nude mice bearing LNCaP human prostate tumor. J Nucl Med. 2003;44:610-617.

36. Holland JP, Divilov V, Bander NH, Smith-Jones PM, Larson SM, Lewis JS. $\mathrm{Zr}$-89-DFO-J591 for immunoPET of prostate-specific membrane antigen expression in vivo. $J$ Nucl Med. 2010;51:1293-1300.

37. Holland JP, Sheh Y, Lewis JS. Standardized methods for the production of high specific-activity zirconium-89. Nucl Med Biol. 2009;36:729-739.
38. Bander NH, Nanus D, Bremer S, et al. Phase I clinical trial targeting a monoclonal antibody $(\mathrm{mAb})$ to the extracellular domain of prostate-specific membrane antigen (PSMAext) in patients with hormone-independent prostate cancer [abstract]. Proc Am Soc Clin Oncol. 2000;19:477a.

39. Bander NH, Nanus D, Goldsmith S, et al. Phase I trial of humanized monoclonal antibody $(\mathrm{mAb})$ to prostate-specific membrane antigen/extracellular domain (PSMAext) [abstract]. Proc Am Soc Clin Oncol. 2001;20:722.

40. Vallabhajosula S, Kuji I, Hamacher KA, et al. Pharmacokinetics and biodistribution of ${ }^{111} \mathrm{In}$ - and ${ }^{177} \mathrm{Lu}$-labeled J591 antibody specific for prostate-specific membrane antigen: prediction of ${ }^{90} \mathrm{Y}-\mathrm{J} 591$ radiation dosimetry based on ${ }^{111} \mathrm{In}$ or ${ }^{177}$ Lu? J Nucl Med. 2005;46:634-641.

41. Morris MJ, Divgi CR, Pandit-Taskar N, et al. Pilot trial of unlabeled and indium111-labeled anti-prostate-specific membrane antigen antibody J591 for castrate metastatic prostate cancer. Clin Cancer Res. 2005;11:7454-7461.

42. Pandit-Taskar N, O'Donoghue JA, Morris MJ, et al. Antibody mass escalation study in patients with castration-resistant prostate cancer using ${ }^{111} \mathrm{In}-\mathrm{J} 591$ : lesion detectability and dosimetric projections for ${ }^{90} \mathrm{Y}$ radioimmunotherapy. $\mathrm{J} \mathrm{Nucl}$ Med. 2008;49:1066-1074.

43. Bander NH, Milowsky MI, Nanus DM, Kostakoglu L, Vallabhajosula S, Goldsmith SJ. Phase I trial of ${ }^{177}$ lutetium-labeled J591, a monoclonal antibody to prostate-specific membrane antigen, in patients with androgen-independent prostate cancer. J Clin Oncol. 2005;23:4591-4601.

44. Holland JP, Caldas-Lopes E, Divilov V, et al. Measuring the pharmacodynamic effects of a novel Hsp90 inhibitor on HER2/neu expression in mice using Zr-89DFO-trastuzumab. PLoS One. 2010;5:e8859.

45. Pandit-Taskar N, O'Donoghue JA, Beylergil V, et al. ${ }^{89} \mathrm{Zr}$-huJ591 immuno-PET imaging in patients with advanced metastatic prostate cancer. Eur J Nucl Med Mol Imaging. 2014;41:2093-2105.

46. Pandit-Taskar N, O'Donoghue JA, Durack JC, et al. A phase I/II study for analytic validation of ${ }^{89} \mathrm{Zr}-\mathrm{J} 591$ immunoPET as a molecular imaging agent for metastatic prostate cancer. Clin Cancer Res. 2015;21:5277-5285.

47. Knowles SM, Wu AM. Advances in immuno-positron emission tomography: antibodies for molecular imaging in oncology. J Clin Oncol. 2012;30:3884-3892.

48. Olafsen T, Sirk SJ, Olma S, Shen CK, Wu AM. ImmunoPET using engineered antibody fragments: fluorine-18 labeled diabodies for same-day imaging. Tumour Biol. 2012;33:669-677.

49. Wong JY, Chu DZ, Williams LE, et al. Pilot trial evaluating an ${ }^{123}$ I-labeled 80-kilodalton engineered anticarcinoembryonic antigen antibody fragment (cT84.66 minibody) in patients with colorectal cancer. Clin Cancer Res. 2004;10:5014-5021.

50. Wu AM, Olafsen T. Antibodies for molecular imaging of cancer. Cancer J. 2008;14:191-197.

51. Wu AM. Engineered antibodies for molecular imaging of cancer. Methods. 2014;65:139-147.

52. Wu AM. Antibodies and antimatter: the resurgence of immuno-PET. J Nucl Med. 2009;50:2-5.

53. Wu AM, Senter PD. Arming antibodies: prospects and challenges for immunoconjugates. Nat Biotechnol. 2005;23:1137-1146.

54. Leyton JV, Olafsen T, Lepin EJ, et al. Humanized radioiodinated minibody for imaging of prostate stem cell antigen-expressing tumors. Clin Cancer Res. 2008;14:7488-7496.

55. Olafsen T, Betting D, Kenanova VE, et al. Recombinant anti-CD20 antibody fragments for small-animal PET imaging of B-cell lymphomas. J Nucl Med. 2009;50:1500-1508.

56. Viola-Villegas NT, Sevak KK, Carlin SD, et al. Noninvasive imaging of PSMA in prostate tumors with ${ }^{89} \mathrm{Zr}$-labeled huJ591 engineered antibody fragments: the faster alternatives. Mol Pharm. 2014;11:3965-3973.

57. Pandit-Taskar N, Joseph O, Lyashchenko S, et al. ${ }^{89} \mathrm{Zr}$-IAB2M minibody imaging in patients with prostate cancer: biodistribution, kinetics, lesion uptake and organ dosimetry [abstract]. J Nucl Med. 2014;55(suppl 1):1670.

58. Kircher MF, Hricak H, Larson SM. Molecular imaging for personalized cancer care. Mol Oncol. 2012;6:182-195.

59. Maurer T, Gschwend JE, Rauscher I, et al. Diagnostic efficacy of ${ }^{68}$ galliumPSMA positron emission tomography compared to conventional imaging for lymph node staging of 130 consecutive patients with intermediate to high-risk prostate cancer. J Urol. 2016;195:1436-1443.

60. Welle CL, Cullen EL, Peller PJ, et al. ${ }^{11} \mathrm{C}$-choline PET/CT in recurrent prostate cancer and nonprostatic neoplastic processes. Radiographics. 2016;36: 279-292.

61. Odewole OA, Tade FI, Nieh PT, et al. Recurrent prostate cancer detection with anti-3-[ $\left[{ }^{18}\right.$ F]FACBC PET/CT: comparison with CT. Eur J Nucl Med Mol Imaging. 2016;43:1773-1783. 